\title{
Predictors of depression among older people living in rural areas of Thailand
}

\author{
Haseen $\mathrm{F}^{1}$, Prasartkul $\mathrm{P}^{2}$ \\ ${ }^{1}$ Health System and Infectious Diseases Division (HSID), ICDDR,B, Mohakhali, Dhaka-1212, Bangladesh, \\ ${ }^{2}$ Institute for Population and Social Research, Mahidol University, Salaya, Nakhon Pathom, 73170, Thailand
}

\begin{abstract}
Global population is ageing and Thailand has one of the fastest growing ageing populations in this region. Combined with this, depression has become a major mental health problem for older people. The objective of this paper is to examine the predictors of depression among rural older people of Thailand. This study has used information from the Study on Health and Social Support among Older Population living in Kanchanaburi Demographic Surveillance System (KDSS), Thailand in 2006. Depression was measured by a 12 item questionnaire of Thai validated Euro-D scale among 1001 respondents. The questions were on depression, pessimism, wishing to die, guilt, sleep disturbance, loss of interest, irritability, eating problems, fatigue, problem in concentration, lack of enjoyment, and tearfulness. Among the respondents $28.5 \%$ had depression. The results of logistic regression found that infirmity, disability and serious life events had significant effect on depression of the respondent. Those who had 4 or more infirmity, they were 2.08 times more likely to have depression compare to those who had no or only 1 infirmity. Disability was another strong predictor of the depression. It should be mentioned here that those who had medium disability, had the chance of depression 3.12 times more compare to those who had no disability. Serious life event was also a major factor for the respondents. Those who had 3 or more serious life events they had the depression 5.25 times more compare to those who had no serious life event.This study identified three major predictors of depression for older people in KDSS, Thailand. The finding will help to design specific prevention program to reduce the depression of older people living in the rural area of Thailand.
\end{abstract}

\section{Introduction}

Depression is a common mental health problem of older people and is associated with considerable morbidity. The prevalence of depression among older people who are living in the community ranges from 15 to 25 per cent, depending on population studied and the categories of disorder examined. Institutionalized elderly could have depression from 10 to 40 per cent with mild to moderate impairments and additional 5 to 10 per cent depression due to severe impairment ${ }^{1}$. Depression in older people has been identified as a new public health problem in low and middle income countries including Thailand ${ }^{2}$. Previous studies had identified multiple factors as predictors of depression in old age which varied with context. Increasing age is one of the important predictor for old age depression ${ }^{3-4}$. Females had higher proportion of depression compare to males ${ }^{5-7}$. The prevalence of depression was found to be significantly higher in the elderly who were single (never married), widowed, divorced or separated ${ }^{8-9}$.
Low education was associated with old age depression $^{10-11 .}$ Unemployment can give rise to reduced hope and financial problem, which in turn contribute to depression ${ }^{12}$. Majority of the older people have one or more chronic conditions and many suffer from multiple physical disorders that restrict their activities ${ }^{13}$. Beside infirmity, disability is an important predictor for old age depression $^{14}$. Death of spouse or financial problem is commonly experienced serious life events for older people ${ }^{15-16}$.

Both in absolute numbers and in proportion, the population aged 60 years and over have increased faster compare to overall population in Thailand. The older population shared of 5.5 per cent in 1980 , about 9.5 per cent in $2000^{17-18}$, and will be about 14.4 per cent in $2020^{19}$. Figure 1 shows the population pyramid of Thailand in 1970, 1990, 2010 and 2030. These pyramids clearly showed how Thai population structure will be transformed from a young population to ageing population within 40 years. 


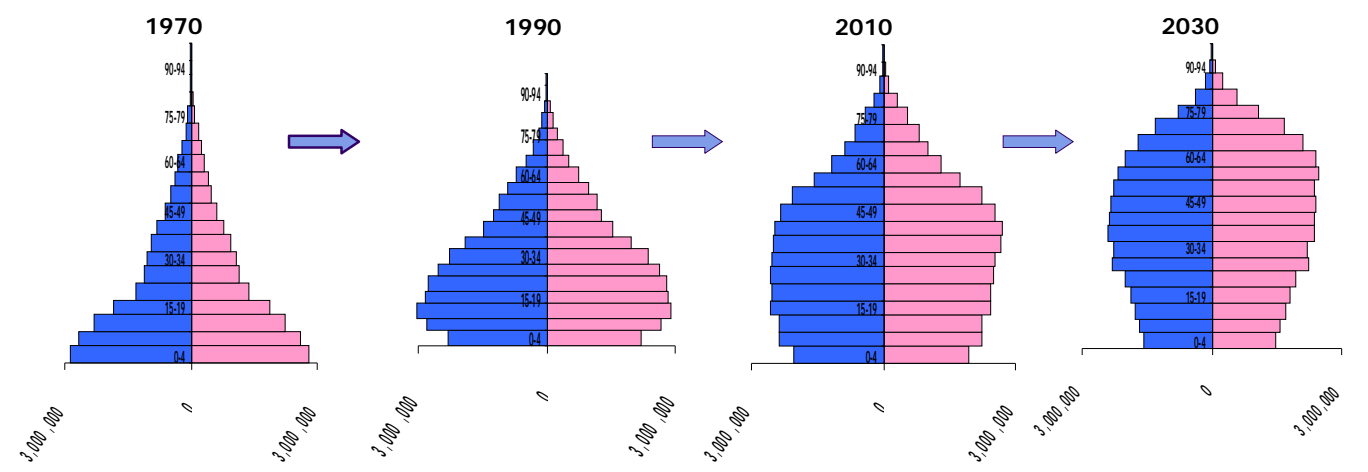

Figure 1: Population pyramid of Thailand from 1970-2030

Source: NSO, 1960-2000, Mahidol University Population Gazette, 2007

As fertility and mortality have decreased and people's life expectancy increased, there is growing concern over the mental health of older people in Thailand. Several studies were conducted on depression in Thailand. Various standardized and mostly validated measurement scales were used. Some studies validated the scales in Thai context, for example, EURO-D, Mini Mental State, Thai mental state examination ${ }^{20-22 .}$ Other studies found that prevalence of depression varied among elderly people. For example the prevalence was 30.0 per cent among displaced adults after tsunami in Thailand, 29.2 per cent among population 45 and older in Chiang Mai province and 12.78 per cent among elderly living in the community ${ }^{23-25}$. Multiple predictors are responsible for depression at old age. Previous studies identified children's migration, psychological wellbeing of elderly, social support to elderly and living arrangement as important predictors ${ }^{26-29}$. But the information on important predictors of depression of older people in Thailand is still not sufficient.

The objective of this paper is to examine the predictors of depression among rural older people of Thailand. The findings will help to design the appropriate mental health programs for the elderly.

\section{Materials and Methods}

This study has used the information from the study on Health and Social Support among Older Population living in Kanchanaburi Demographic Surveillance System (KDSS), Thailand in 2006. The survey was conducted by Institute for Population and Social Research (IPSR), Mahidol University, Thailand in collaboration with Kings College, London, UK. Data were collected from November 2006 to January 2007. This study was approved by the ethics committee of the Mahidol University.

Dependent variable

Depression: Depression was measured by using a Thai version of the EURO-D scale questionnaire ${ }^{30}$.
The EURO-D scale is a structured scale of depressive symptoms designed for detecting depression in older populations. It can be used as a self-administered tool. The questions were read out here. Thai mental health professionals, including two non English-speaking locally trained providers, considered that it covered symptoms recognized locally as common in psychological disorders in older adults. A team of bilingual mental health professionals, bilingual social scientists and English psychiatrists did the first translation, paying particular attention to conceptual and semantic equivalence. Eight Thai psychiatrists validated the Thai version of the EURO-D in an out-patient setting against the Thai version of the Mini International Neuropsychiatric Interview. This is a standardized clinical diagnostic interview for DSM-IV Axis-I disorders ${ }^{31}$ Based on the cut-of point of $5 / 6$, the area under the ROC curve was 0.78 [ $95 \%$ confidence intervals $(\mathrm{CI}) 0.70-0.85$ ], the kappa was 0.4 and internal consistency for the total scale measured by Cronbach's alpha was $0.72^{30}$. The total score ranged from 0-12 and categorized in two groups, case and no case ${ }^{28}$.

\section{Independent variables}

Age: The variable was grouped in three categories, $60-69,70-79$ and 80 years and more. The variables were assigned as 60-69 years $=1,70-79$ years $=2$ and 80 years and more $=3$.

Gender: Gender was grouped in male and female. The response categories were assigned as male $=0$, female $=1$.

Educational level: Three categories were made, those who did not go to the school were assigned as 'no education $=0,1-3$ years $=1, \& 4$ years or more $=2$. Marital status: Under marital status the response categories were married, separated, divorced, single and widow. Then it was categorized as married $=1$, separated/ divorced/single $=2$ and widow $=3$.

Working status: Two categories were there, working $=0$ and not working $=1$. 
Infirmity: A modified version of the Burvill physical illness scale $(1990)^{32}$ covering the presence of 13 common health problems affecting different systems, including breathlessness, blackouts, arthritis, weakness, hearing difficulties and heart trouble. Every item has two response options (1=yes, $0=$ no). A composite index was developed from all 13 responses. The total score was $0-13$. Then the index was categorized in three groups, '0-1 infirmity', '2-3 infirmity' and ' 4 or more infirmity'.

Disability: The brief version of the World Health Organization's Disability Assessment Schedule was used to rate disability over the past 30 days. The questions included understanding and communicating with the world, getting around, self-care, getting along with people, activities and participation in society. The "disability in last 30 days' was assessed by 11 questions. Every question had 4 options: none, mild, severe and extreme/ cannot do and had score from $0-3$. The total score was 0-33. A composite index was created. The index was categorized in four groups, 0 score grouped as 'no disability', 1-11 score assigned as 'low disability', 11-22 scores were grouped under 'medium disability' and 23-33 score categorized as 'high disability'.

Serious life events: The list of Threatening Experiences in the light of qualitative work ${ }^{33}$ and following advice from experts in measuring life events in older people. The adaptation included difficulties as well as events, restricting rating of events and difficulties to those remaining severe for over 3 weeks that occurred to the participant, an immediate family member or someone perceived as 'very close', and adding events for example, to do with caring for grandchildren ${ }^{34}$. Six questions were selected for this study to measure the effect of serious life events which caused difficulty more than 2-3 weeks in the current year. Every item has two response options $(1=y e s, 0=$ no). A composite index was developed from the questions: illness, lack of contact with children, financial problem, accommodation, health problem of family member and care giver burden. The total score was 0-6. Then the index was categorized into three groups. 'no serious life event', '1-2 serious life events' and more than 2 serious life events'.

Analysis: First, univariate analysis was done to describe the percentage of the respondents' prevalence of depression, socio-demographic characteristics, infirmity, disability and serious life events. Bivariate analysis with chi-square test was performed to identify associated factors to the depression. The variables were further examined in the multivariate analysis (logistic regression) in order to identify the significant predictors of depression after controlling for other variables. During the process of analysis, multi-collinearity among the variables was assessed. As there was high collinearity between working status and current occupation was found, current occupation was dropped from the multivariate analysis. Other variables were not highly correlated and they were included in the logistic model.

\section{Results}

The prevalence of depression was 27.5 percent. Most of the respondents were 60-69 years of old, had 4 years or more schooling and married (Table I). Around 54 per cent respondents had more than 3 infirmities (Figure 2), low disability (Figure 3 ) and 1-2 serious life events (Figure 4).

Table 1: Socio-demographic characteristics of elderly people in rural KDSS, Thailand, 2006

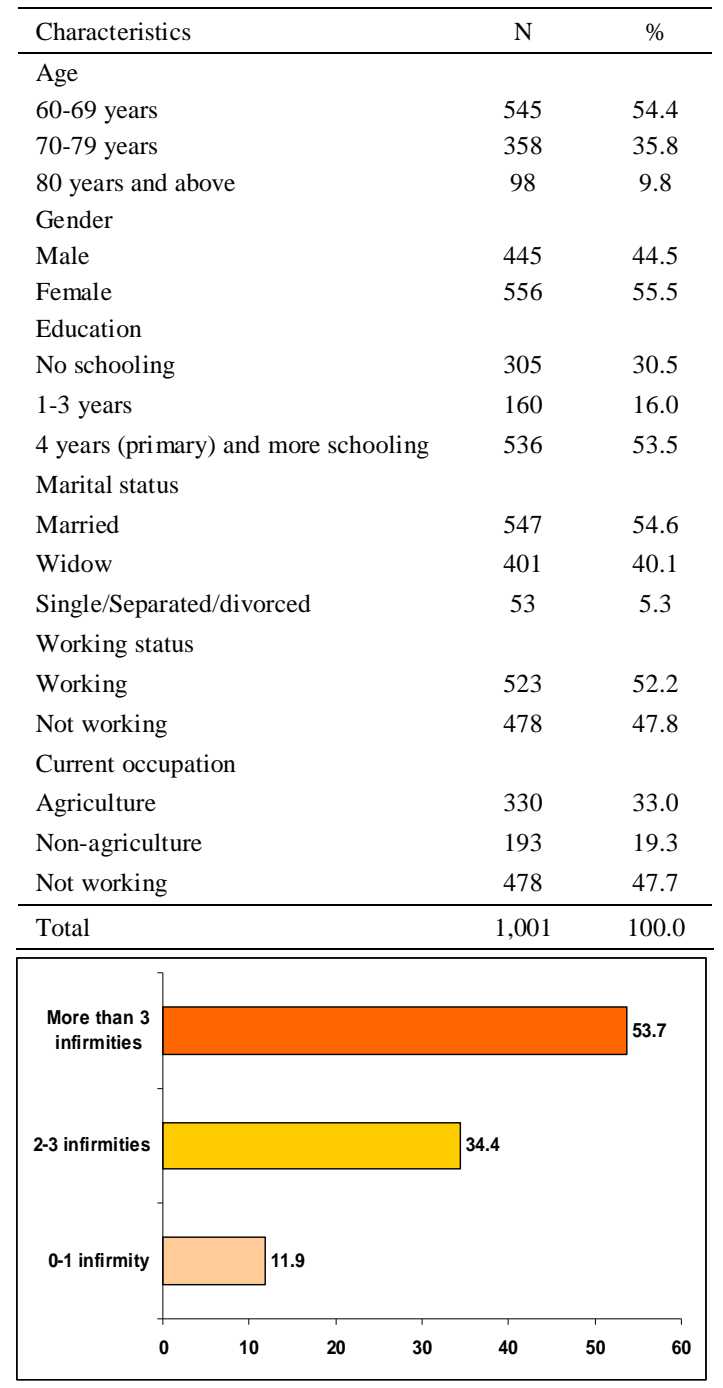

Figure 2: Infirmity among elderly people in rural KDSS, Thailand, 2006, $(n=1,001)$ 


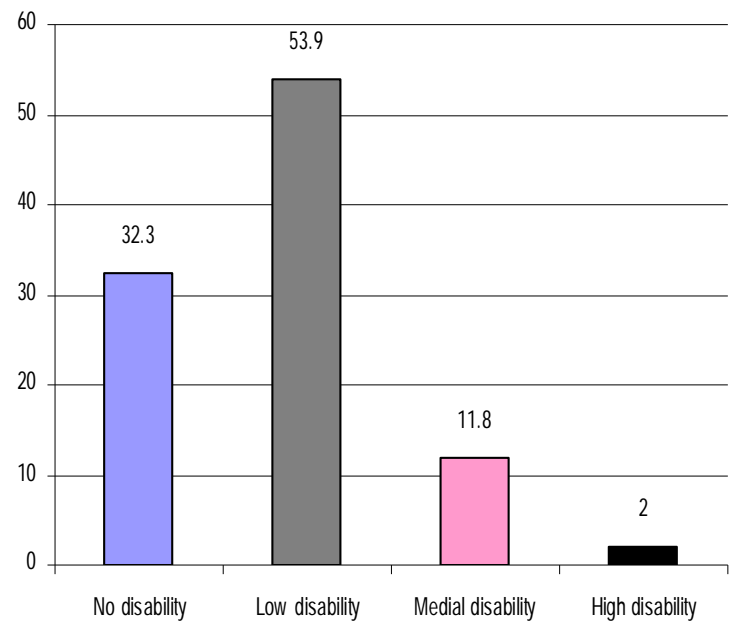

Figure 3: Disability among elderly people in rural KDSS, Thailand, 2006, $(n=1,001)$

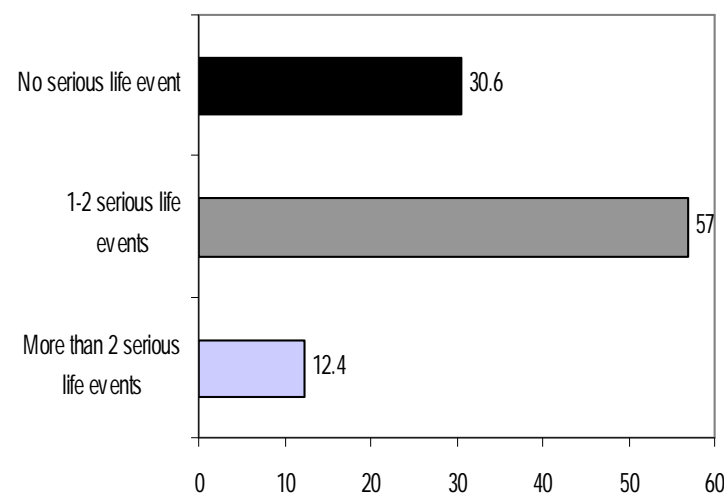

Figure 4: Serious life events among elderly people in rural KDSS, Thailand, 2006, $(n=1,001)$

In bivariate analysis, depression had highly significant association ( $\mathrm{p}$ value: 0.001 ) with age, gender, education, marital status, working status, current occupation, infirmity, disability, serious life events and self-assessed health. The oldest old had higher proportion of depression compare to younger old. Female had higher proportion of depression compare to male. Those had no schooling or less than 4 years of schooling, had more depression compare to those had 4 years and more schooling. Widow and separated/divorced/single respondents had higher proportion of depression compare to married. The working respondents and those who worked in the agriculture sector had less depression compare to not working and working in nonagriculture sector. The respondents who had more than 3 infirmity or health problems, and medium or high disability had higher proportion of depression compare to those had no or less infirmity and disability (Table II).
The results of binary logistic regression found that infirmity, disability and serious life events had significant effect on depression of the respondent. Physical health played an important role for these respondents' mental health. Those who had 4 or more infirmity, they were 2.08 times more likely to have depression compare to those who had no or only 1 infirmity. This indicates that the multiple diseases are strong risk factor for the depression at late age. Disability was another strong predictor of the depression. It should be mentioned here that those who had medium disability, had the chance of depression 3.12 times more compared to those who had no disability. Serious life event is another major factor for the respondents. Those who had 3 or more serious life events they had the depression 5.25 times more compare to those who had no serious life event in last year (Table III).

Table II: Depression of elderly people with selected characteristics in rural KDSS, Thailand, 2006

\begin{tabular}{|c|c|c|c|}
\hline & & Depression & Total \\
\hline \multirow[t]{3}{*}{ Age $* * *$} & $60-69$ years & 22.4 & $545(100.0)$ \\
\hline & $70-79$ years & 34.6 & $358(100.0)$ \\
\hline & 80 years and above & 39.8 & $98(100.0)$ \\
\hline \multirow[t]{2}{*}{ Gender*** } & Male & 19.3 & $445(100.0)$ \\
\hline & Female & 35.8 & $556(100.0)$ \\
\hline \multirow[t]{3}{*}{ Education $* * *$} & No schooling & 37.7 & $305(100.0)$ \\
\hline & 1-3 years schooling & 31.9 & $160(100.0)$ \\
\hline & 4 years (primary) \& more & 22.2 & $536(100.0)$ \\
\hline \multirow[t]{3}{*}{ Marital status*** } & Married & 22.1 & $547(100.0)$ \\
\hline & Widow & 36.2 & $401(100.0)$ \\
\hline & Separated/divorced/singe & 35.8 & $53(100.0)$ \\
\hline \multirow[t]{2}{*}{ Working status**** } & Working & 22.2 & $523(100.0)$ \\
\hline & Not working & 35.4 & $478(100.0)$ \\
\hline \multirow{3}{*}{$\begin{array}{l}\text { Current } \\
\text { occupation*** }\end{array}$} & Agriculture sector & 18.2 & $330(100.0)$ \\
\hline & Non-Agriculture sector & 29.0 & $193(100.0)$ \\
\hline & Not working & 35.4 & $478(100.0)$ \\
\hline \multirow[t]{3}{*}{ Impairment $* * *$} & 0-1 impairment & 5.9 & $119(100.0)$ \\
\hline & 2-3 impairments & 18.3 & $344(100.0)$ \\
\hline & $\begin{array}{l}\text { More than } 3 \\
\text { impairments }\end{array}$ & 40.0 & $538(100.0)$ \\
\hline \multirow[t]{4}{*}{ Disability*** } & No disability & 9.3 & $323(100.0)$ \\
\hline & Low disability & 32.2 & $540(100.0)$ \\
\hline & Medium disability & 57.6 & $118(100.0)$ \\
\hline & High disability & 65.0 & $20(100.0)$ \\
\hline \multirow{3}{*}{$\begin{array}{l}\text { Serious life events } \\
\text { in last } 1 \text { year*** }\end{array}$} & No serious life event & 13.1 & $306(100.0)$ \\
\hline & 1-2 serious life events & 30.3 & $571(100.0)$ \\
\hline & $\begin{array}{l}\text { More than } 2 \text { serious } \\
\text { life events }\end{array}$ & 58.1 & $124(100.0)$ \\
\hline Total & & & $1,001(100.0)$ \\
\hline
\end{tabular}


Table III: Adjusted odds ratio (OR) of depression among older people by selected characteristics in KDSS, Thailand in 2006

\begin{tabular}{|c|c|c|c|c|}
\hline Variable & & $\begin{array}{l}\text { Odds } \\
\text { ratio }\end{array}$ & Std. Err. & $\begin{array}{l}\text { Sig. } \\
\text { level }\end{array}$ \\
\hline \multirow[t]{3}{*}{ Age } & $60-69$ years (ref) & 1.00 & & \\
\hline & $70-79$ years & 0.96 & 0.2652639 & 0.891 \\
\hline & 80 years and above & 5.06 & 5.327 & 0.122 \\
\hline \multirow[t]{2}{*}{ Gender } & Male (ref) & 1.00 & & \\
\hline & Female & 1.43 & 0.4106525 & 0.206 \\
\hline \multirow[t]{3}{*}{ Education } & Primary or more (ref) & 1.00 & & \\
\hline & 1-3 years & 2.17 & 0.9855232 & 0.087 \\
\hline & No schooling & 1.31 & 0.4107729 & 0.384 \\
\hline \multirow[t]{3}{*}{ Marital status } & Married (ref) & 1.00 & & \\
\hline & Widow & 0.88 & 0.2692485 & 0.694 \\
\hline & Separated/divorced & 2.11 & 1.593958 & 0.319 \\
\hline \multirow[t]{2}{*}{ Work } & Working (ref) & 1.00 & & \\
\hline & Not working & 0.76 & 0.2112423 & 0.324 \\
\hline \multirow[t]{3}{*}{ Infirmity } & $0-1$ (ref) & 1.00 & & \\
\hline & $2-3$ & 1.02 & 0.3236875 & 0.933 \\
\hline & $4+$ & 2.08 & 0.7473537 & 0.041 \\
\hline \multirow[t]{4}{*}{ Disability } & No disability (ref) & 1.00 & & \\
\hline & Low disability & 1.25 & 0.3489871 & 0.416 \\
\hline & Medium disability & 3.12 & 1.3924 & 0.011 \\
\hline & High disability & 3.81 & 4.008688 & 0.203 \\
\hline \multirow[t]{3}{*}{$\begin{array}{l}\text { Serious life } \\
\text { events }\end{array}$} & $\begin{array}{l}\text { No serious life } \\
\text { events }\end{array}$ & 1.00 & & \\
\hline & $1-2$ & 1.50 & 0.3744883 & 0.098 \\
\hline & $3+$ & 5.25 & 3.941786 & 0.027 \\
\hline
\end{tabular}

N1 $=1001$, Pseudo R square $=0.1255$, Sig. $=0.0000$

\section{Discussion}

This study found multiple predictors are responsible for depression of the older people living in the rural KDSS area of Thailand. They are the infirmity, disability and serious life events. Life expectancy at birth increased from 58.0 years for males and 63.8 years for females in $1975^{34}$ to 69.5 for males and 76.3 for females in $2010^{35}$. The recent data of Thailand shows that proportion of people suffering from chronic diseases and disability is increasing. Other studies also found that majority of the older people have one or more chronic conditions and many suffer from multiple physical disorders that restrict their activities ${ }^{13,16}$. According to National Health Statistics the leading burden of disease in Thai population has been shifting to non-communicable diseases ${ }^{36 .}$ But the socio-demographic factors were not significant to predict depression of older people. We found that the proportion of depression increased with age. Although our finding is different from previous research which found that overall distress and anxiety decreases with age, it is consistent with past literature indicating that depressive symptoms significantly increase with age $\mathrm{e}^{37-38}$.

This study identified three major predictors of depression of older people in Thailand. The policy makers should consider these predictors to design mental health program for older people in Thailand.

\section{References}

1. Hooyman N, Kiyak HA. Social Gerontology. A multidisciplinary perspective. 8th edition. Pearson: 2009.

2. World Health Organization. Mental health development: targeting people with mental health conditions as a vulnerable group. Mental health and poverty project, 2010.

3. Wongpakaran N. Geriatric Psychiatryi Thailand. Journal of Psychiatric Association of Thailand 2008; 53 (supplement 1): 39S-46S.

4. Grammatikopoulos I., Koutentakis C. Social activity and participation as determinants of anxiety and depression among elderly in primary care. Annals of General Psychiatry 2010; 9:137.

5. Sherina M, Rampal LS, Aini M, Norhidayati HM. The prevalence of depression among elderly in an urban area of Selangor, Malaysia. The International Medical Journal 2005; 4(2): 57-62.

6. Bojorquez-Chapela I, Villalobos-Daniel VE, Manrique-Espinoza BS, Tellez-Rojo MM, SalinasRodríguez A. Depressive symptoms among poor older adults in Mexico: prevalence and associated factors. Pan American Journal of Public Health 2009; 26(1): 70-77.

7. Wangtongkum S, Sucharitakul $\mathrm{P}$, Wongjaroen $\mathrm{S}$, Maneechompoo S. Prevalence of depression among a population aged over 45 Years in Chiang Mai, Thailand. Journal of Medical Association of Thailand 2008: 91(12):1812-1817.

8. Taqui AM, Itrat A, Qidwai W, \& Qadri Z. Depression in the elderly: does family system play a role? A crosssectional study. BMC Psychiatry 2007; 7: 57.

9. Jones RN, Marcantonio ER, Rabinowitz T. Prevalence and correlates of recognized depression in U.S. nursing homes. Journal of the American Geriatrics Society 2003; 51(10): 1404-1409.

10. McCall N T, Parks P, Smith K, Pope G, Griggs M. The prevalence of major depression or dysthymia among aged Medicare Fee for service beneficiaries. Int $\mathbf{J}$ Geriatr Psychiatry 2002; 17(6): 557-565.

11. Abolfotouh MA, Daffallah AA, Khan MY, Khattab M S, Abdulmoneim I. Psychosocial assessment of geriatric subjects in Abha City, Saudi Arabia. Eastern Mediterranean Health Journal 2001; 7(3): 481-491.

12. Stankunas M, Kalediene R, Starkuviene $\mathrm{S}$, Kapustinskiene V. Duration of unemployment and depression: a cross-sectional survey in Lithuania. BMC Public Health 2006; 6:174.

13. Aiken LR. Aging and later life. Growing old in modern society. Charles C. Thomas Publisher Ltd. Springfield, Illinois, USA, 2001.

14. Blazer DG. Depression in Late Life: Review and Commentary. Medical Sciences 2003; 58A(3): 249265.

15. Jariwala V, Bansal RK, Patel S, Tamakuwala B. A Study of Depression among Aged in Surat City. 
National Journal of Community Medicine 2010; 1:4749.

16. Fiske A, Wetherell JL, Gatz M. Depressive Symptoms and Aging: The Effects of Illness and Non-health Related Events. Journal of Gerontology: Psychological Sciences 2003; 58:320-28.

17. National Statistical Office. Population and Housing Census. Thailand: National Statistical Office, Office of the Prime Minister, 1980.

18. National Statistical Office. Population and Housing Census. Thailand: National Statistical Office, Office of the Prime Minister, 2000.

19. United Nations. (UN). World Population Prospects: The 2000 Revision. 1, comprehensive tables. Department of Economic and Social Affairs. New York, 2001.

20. Jirapramukpitak T, Darawuttimaprakorn N, Punpuing $\mathrm{S}$, Abas M. Validation and factor structure of the Thai version of the EURO-D scale for depression among older psychiatric patients. Aging \& Mental Health 2009; 13(6):899-904.

21. Silpakit O, Silpakit C, Pukdeenaul P. Comparison study of cognitive impairment screening tools: CDT, IQCODE vs MMSE. Siriraj Medical Journal 2007; 59: 361-363.

22. Train The Brain Forum Committee. Thai Mental State Examination (TMSE) Geriatric Depression Scale. Siriraj Hospital Gazette 1993; 45(6):360-374.

23. Van Griensven F, Chakraband MLS, Thienkrua W, Pengjuntr W, Gardazo BL, et al. Mental Health problems among adults in Tsunami-affected areas in Southern Thailand. Journal of the American Medical Association 2006; 296(5):537-548.

24. Wangtongkum S, Sucharitakul P, Wongjaroen S, Maneechompoo S. Prevalence of depression among a population aged over 45 Years in Chiang Mai, Thailand. Journal of Medical Association of Thailand 2008; 91(12): 1812-1817.

25. Thongtang O, Sukhatunga K, Ngamthipwatthana T, Chulakadabba VS, Pooviboonsuk P, Kooptiwoot S, Phattharayuttawat S. Prevalence and incidence of depression in the Thai elderly. Journal of the Medical Association of Thailand 2002; 85(5): 540-544.

26. Abas M, Punpuing S, Jirapramupitak T, Guest P, Tangchonlatip K, Leese M, Price M. Rural-urban migration and depression in ageing family members left behind. The British Journal of Psychiatry 2009a; 194: 1-7.
27. Abas M, Punpuing S, Jirapramupitak T, Tangchonlatip K, Leese M. Psychological wellbeing, physical impairments and rural aging in a developing country setting. Health and Quality of Life Outcomes 2009b;7: 66.

28. Suttajit S, Punpuing S, Jirapramukpitak $\mathrm{T}$, et al. Impairment, disability, social support and depression among older parents in rural Thailand. Psychological Medicine 2010; 40(10): 1711-1721.

29. Dharawuttimaprakorn N, Punpuing S. Living arrangements and elderly depression: Kanchanaburi DSS, Thailand. Paper presented in Population Association of America, 2010 Annual Meeting in Dallas, Texas, April 15-17, 2010.

30. Prince MJ, Reischies F, Beekman AT, et al. Development of the EURO-D scale-a European Union initiative to compare symptoms of depression in 14 European centres. The British Journal of Psychiatry 199; 174: 330-338.

31. Kittirattanapaiboon $\mathrm{P}, \mathrm{Khamwongpin} \mathrm{M}$. The validity of the Mini International Neuropsychiatric Interview (M.I.N.I.)-Thai Version. Journal of Mental Health of Thailand 2005; 13:126-136.

32. Burvill PW, Mowry B, \& Hall WD. Quantification of Physical Illness in Psychiatric Research in the Elderly. International Journal of Geriatric Psychiatry 1990; 5: 161-70.

33. Brugha TS, Cragg D. The List of Threatening Experiences: the reliability and validity of a brief life events questionnaire. Acta Psychiatrica Scandinavica 1990; 77-81.

34. National Statistical Office. (1997). Report on the 19951996 survey of population change, Bangkok, Thailand: National Statistical Office.

35. Institute for Population and Social Research. Mahidol University Population Gazette. Nakhon Pathom, Thailand: Institute for Population and Social Research, Mahidol University, 2010.

36. Aiken, L.R. Aging and Later Life. Growing old in modern society. Charles C. Thomas Publisher Ltd. Springfield, Illinois, USA, 2001.

37. Nelson CJ, Weinberger MI, Balk E, Holland J, Breitbart W, \& Roth AJ. The chronology of distress, anxiety, and depression in older prostate cancer patients. The Oncologist 2009; 14: 891-899.

38. Aekplakorn W. Non-Communicable Diseases in Urban Communities. Siriraj Medical Journal 2010; 62: 36-38. 